\title{
An Investigation of Thermal Comfort of Woolpeach Modest-Fashion Products: A Case Study in Indonesia
}

\author{
Endang Prahastuti ${ }^{1 *}$ Siti Zahro ${ }^{2,}$ Hapsari Kusumawardani ${ }^{3,}$ Siti Hasanah $^{4,}$ Sri \\ Wahyuningsih Hamar
}

\author{
1,2,3,4,5 Department of Industrial Technology, UniversitasNegeri Malang \\ *Corresponding author, Email: endang.prahastuti.ft@um.ac.id
}

\begin{abstract}
Woolpeach is a type of fabrics made of $100 \%$ polyester with best-selling record in Indonesian market. Muslims form the largest population in Indonesian, and it is not surprising that they wear modest-fashion, usually made of woolpeach fabrics, in performing their daily activities. Therefore, this research wants to know thermal comfort of woolpeachwhen used in creating modest-fashion products in relation to tropical climate of Indonesia. This research used three indicators to know thermal comfort of the modest fashion made of woolpeace, including: 1) thermal insulation of heat, 2) water vapor permeability, and 3) air permeability. Qualitative method was used in this study to deeply know the reaction of participants tothe uses of the modest fashion made of woolpeace fabrics. Twenty students in fashion department in Malang State University were involved as participants in this research. The results of this research shows that 1) most of the participants agreed that modest fashion made of woolpeach fabrics is comfortable to wear in daily activities, which means they did not feel hot, 2) woolpeachcan absorb their sweat, and 3) woolpeach is a fabricwhich can produce cold sensation.
\end{abstract}

Keywords: woolpeach, thermal comfort, modest fashion

\section{INTRODUCTION}

Considered one of the basic human needs, fashion will continue to stimulate an interesting discussion throughout human civilization. Both informal and academic discussions about fashion in the form of scholarly articles follow the fashion trends.From a psychological point of view about fashion industry, women's fashion products have dominated the fashion market more than those of kids and men.In terms of either amount of variation or rapid changes, they are far superior to the other two.

The spread and development of Islam worldwide have recently contributed to the growth of the trend in women's fashion towards modest fashion. The world's most populous Muslim-majority country, Indonesia is considered the trendsetter of modest fashion in the world (CNN Indonesia, 2016). Some Indonesian modest-fashion designers have participated actively in the fashion world: Dian Pelangi and Etu who have penetrated runway London Fashion Week and Japan Fashion Week respectively. This suggests that modest-fashion commodities enjoy a considerable reputation in the fashion world.

Furthermore, modest fashion begins to attract interests of researchers worldwide.Some research on modest fashion studies the increasing use of modest-fashionproducts (Bin Nafisah, 2016). A case study in Turkeyeon the importance of comfort found that comfort and precise measurements are major factors for potential buyers to consider in choosing clothes (Kaplan andOkur, 2007).
In 2017, many modest fashion products in circulation in online trading were made of woolpeachmaterial. This fabric is a mixture of cotton and synthetic fibers, so that it has all good quality of the fibers. One of the basic materials for clothes, woolpeachhas many advantages in that it is soft, smooth, fairly thick but light and not transparent.But what is most important is that it is sold at a price even lower-middle-classed citizens can afford.Such useful features are a perfect combinationfor the making of modest fashion productsbecause to make a single modestfashion product, we need more than three-meter-long fabric,considering modest-fashion products' nature to cover almost all parts of the users'body, from neck to toe. It is important that modest-fashion products are comfortable enough to wear on account of its covering most of all human body. In this term, the standards for thin-bodied users' comfort may indeed differ from those of fat-bodied ones. Therefore, ideal body shapes form the logical choice as a common standard at least for two reasons: (1) most of the female population has the ideal body shape and (2) from the persective of physiological mechanisms, it produces a fair number of sweat beads. In fact, little have we read research thoroughly examining thisgradually-emerging fashion trend although woolpeachmade modest-fashion products have widely spread.For this reason, this research finds it important to carry out research on the comfort level of M-sized modest-fashion products made of woolpeach in everyday uses. Given the 
"Weeks and high On a general, people may have different standards on modest fashion, as long as it does not involve flashing the flesh. Modest fashion across religions has a great point of consensus that it should not be experienced as a limiting factor in style. Today, modest street style is thriving and can be visibly noticed during fashion -end events" (https://en.wikipedia.org/wiki/Modest_fashion)

In time modest fashion intensifies a worldwide marketing campaign throughe_commers, social media, and other non-traditional markets. This attracts interest of world-class designers such as Dolce \&Gabbana, danMax Mara in partaking in designing modest-fashion products, which causes Muslim women not to be the only target consumers of modest fashion (https://www.forbes.com/sites/deborahweinswig/2017/03/ 31/is-modest-fashion).

Modest fashion products on trend are no more limited in the form of Muslim traditional, old-fashioned clothes. Today this fashion models becomes exclusive high fashion that is sold at exorbitant prices. Here are some latest designs of modest fashionproduced by a fashion house of Dolce \&Gabbana and put on the high-fashionmarket.

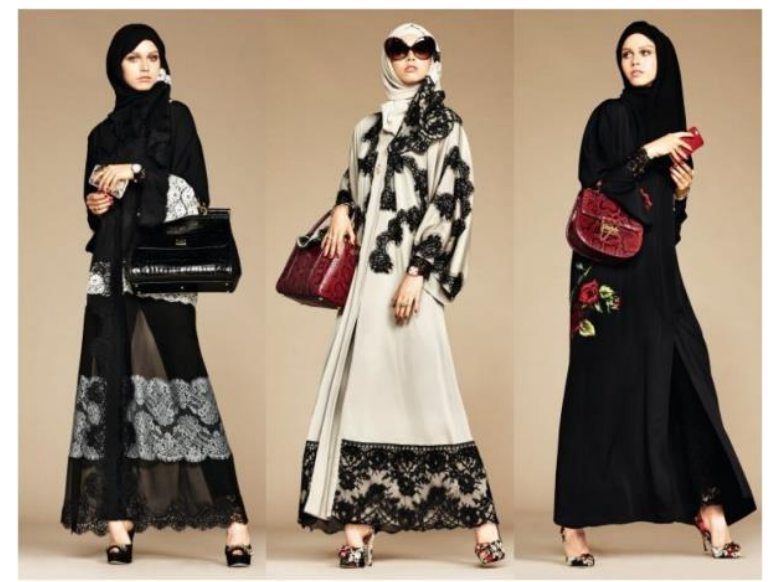

(Dolce \&Gabbana's New Hijab Collection, 2017)

\subsection{Comfortability of Fashion}

In addition to visual appearances, some parts of fashion products deal with human comfort felt when someone wears them. A fashion product can be considered comfortable if it is made neither too loose nor too tight, which enables its users to feel undisturbed, safe and free to move and by turns builds up their confidence.

Nowadays consumers prefer to choose clothes in which they look fancy and feel comfortable. As a consequence, comfortability forms a parameter of fashion products. Malik, (2012:55) defined "Comfort as a pleasant state of physiological, psychological and physical harmony between a human being and the environment."

Comfortability of fashion deals with some aspects including 1) thermo physiological, 2) sensorial, 3) body movement, and 4)aesthetic appeal(Bhatia and Malhotra, 2016:volume 6). A study in Turkeyediscoveres a corroborative evidence for this statement that comfortability of fashion is attributed to six factors plus one factor difficult to categorize: 1) aesthetic, 2) structural, 3) thermal, 4) disturbing, 5) sensory, 6) mechanical, dan 7) others (Kaplan\&Okur, 2007). Nonetheless, not all of the factors the two statements identified are possible to be considered in fashion products because they also depend on mode, material, danthe purpose of the related research. Therefore, in setting modest fashion as a research objective, this research identifies factors in fashion comfortability in accordance with the essential needfor which modest fashion is used. Those factors are 1) aesthetic comfort, 2) structural comfort, and 3) thermal comfort.

Aesthetic comfortrelates to the sense of beauty clothes convey. Aesthetic comfort includes 1) colors, 2) designs, 3) precise measurement, and 4) fabric construction.

Structural comfortrelates to the physical features of fashion products which include 1) perfectly-created structures, 2) volume, 3) durability, and 4) thickness. 
Meanwhile, thermal comfortrelates to thermal environment, especially hot air, felt when one wears a fashion product. Some factors attributed to this comfort are1) heat insulation, 2) sweat absorption, and 3) air permeability.

\subsection{Sizes of Modest-Fashion Products}

Fashion productsare manufactured to cover people's body, but unfortunately, those available in markets cannot always fit varying body shapes and sizes of their
users.Therefore, many fashion companies mass-produce clothes in standardized sizes, determined on the basis of the most frequently visiting consumers' body measurements.

In Indonesia, Zoya is considered one of the modestfashion producerswith a stellar reputation.Zoya's products are made in the following size chart.

Table 2.1. S / M / L / XL/ XXL Sizes of 'ZOYA'

\begin{tabular}{|c|c|c|c|c|c|}
\hline \multirow[t]{2}{*}{ Body Measurements } & \multicolumn{5}{|c|}{$\begin{array}{lllll}\begin{array}{l}\text { Standard } \\
\text { Products }\end{array} & \text { Sizes of Zoya's } & \text { Modest-Fashion } \\
\end{array}$} \\
\hline & $\mathbf{S}$ & $\mathbf{M}$ & $\mathbf{L}$ & $\mathbf{X L}$ & XXL \\
\hline Body ciurcumference & 94 & 100 & 106 & 112 & 120 \\
\hline Waist circumference & 87 & 93 & 99 & 105 & 113 \\
\hline Pelvis circumference & 100 & 106 & 112 & 120 & 128 \\
\hline Shoulder width & 11.5 & 12 & 12.5 & 13.5 & 14 \\
\hline Arm length & 54 & 56 & 58 & 60 & 60 \\
\hline Wrist circumference & 34 & 35 & 36 & 38 & 39 \\
\hline Manset size & 22 & 22.5 & 23 & 23 & 23.5 \\
\hline Collar circumference & 46 & 46 & 47 & 48 & 48 \\
\hline Tunic Length & 85 & 85 & 85 & 85 & 85 \\
\hline Dress Length & 138 & 138 & 138 & 138 & 138 \\
\hline
\end{tabular}

http://www.milazone.com/blog-285-detail-size-zoya.html, accessed on March 18, 2018.

Some body measurements necessary for making modestfashion products are not mentioned on the table above, so that for the purpose of data collection, the researcher needs to modify the listed measurements by increasing or decreasing their sizes.Commonly, Indonesian fashion industry uses the standard S, M, L, XL, and XXL sizesto offer costumers broad ranges of sizes from small/thin sizes to large/fat sizes. However, in fact, many fashion companies commonly produce clothes in $\mathrm{M}$ size more than in other sizes taking into consideration the fact that $\mathrm{M}$ size satisfies most consumers' demands. In other words, the most frequently visiting consumers are women in $\mathrm{M}$ size. The following is the standard $M$ size of mosedtfashion products and body measurements of consumers involved in this research as repondents.

Table 2.2. Standard Size of Modest-Fashion Products and Respondents' Body Measurements

\begin{tabular}{|l|l|l|}
\hline Standard Size of Modest-Fashion Products & M & Tolerance \\
\hline Body circumference & 100 & \\
\hline Waist circumference & 93 & \\
\hline Pelvis circumference & 106 & \\
\hline Back length & 38 & \\
\hline Shoulder width & 12 & \\
\hline Upper-back width & 36 & \\
\hline Sleeve circumference & 48 & \\
\hline Upper-arm circumference & 40 & \\
\hline Wrist circumference & 34 & \\
\hline Dress length & 138 & \\
\hline Body Measurement & & \\
\hline Body circumference & 96 & -2 to $+2 \mathrm{~cm}$ \\
\hline Waist circumference & 89 & -2 to $+2 \mathrm{~cm}$ \\
\hline Pelvis circumference & 102 & -2 to $+2 \mathrm{~cm}$ \\
\hline
\end{tabular}

(milazone.com. modified by Prahastuti) 
This research is planned to be qualitative and descriptive research.To obtain comprehensive data about comfortability of M-sizedwoolpeach modest-fashion products, the researcher asked some respondentsto wear them during a 3-hour-long learning activity in a laboratory,during and after which the researcher interviewed the respondents while observing their expressions and movements and filming a visual documentary.

\subsection{The Researcher's Participation}

In his direct participation, the researcher led the workshop and at the same time filmed all repondents' activities in woolpeach-made, modest-fashion products for e hours.In short, the researcher served as an observer, a data collector, and a data analyst (Arikunto,2002:15).

The active involvement of both the researcher and the participants in the workshop, as a leader and members respectively,gave the researcher an ease with which to collect data about their feeling, responses, and other detailed, research-related information. This helped ensure the validity and reliability of the qualitative data.

\subsection{Data Sources and Reseacrh Location}

The respondents involved in this research are undergraduate students who in 2014 and 2015 registered at Fashion Department of Malang State University.They are those with M-sized body measurements. Those students were selected as participants based on an assumption that after taking the course on techniques for creating women's fashion products and the course on textiles, fashion students are expected to have some competencies needed to accomplish the purpose of this research. Therefore, they could wear the M-sized clothes and assessed the quality of those clothes. There were 51 students registering in 2014 and 61 students registering in 2015 actively attending class activities. Of all those students, the researcher selected 20 students in total as the respondents of this research: 14 students from those registering in 2014 and 6 students from those registering in 2015. The selection process is shown in the following table 3.1.

Table 3.1. The Total Numbers of Respondents

\begin{tabular}{|l|l|l|}
\hline Registration Years & $\begin{array}{l}\text { The Total Number } \\
\text { of Students }\end{array}$ & $\begin{array}{l}\text { The Total Number of Respondents with M-sized } \\
\text { Body Measurements }\end{array}$ \\
\hline 2014 & 51 & 14 \\
\hline 2015 & 61 & 6 \\
\hline The Total Number of Respondents & 20 \\
\hline
\end{tabular}

This research was conducted in a workshop on modest fashion in the fashion laboratory of Malang State University.The laboratory is the 8-meter $\mathrm{x} 11$-meterwideroom with a temperature of $33^{\circ} \mathrm{C}$ (The temperature measurement is mentioned in appendix 4).

\subsection{Research Instruments}

Qualitative data about comfortability of Msizedwoolpeach modest-fashion products were collected using some instruments, including interviews, observations, and documents. The interview was conducted under a set of guidelines as shown in the following table. 
Table 3.2 Instruments

\begin{tabular}{|l|c|}
\hline Research Focus & Indicators \\
\hline Thermal comfort of M-sized & 1) Thermal insulation of heat \\
\cline { 2 - 2 } $\begin{array}{l}\text { woolpeach modest-fashion } \\
\text { products }\end{array}$ & 2) Water vapor permeability \\
\cline { 2 - 3 } & 3) Air permeability. \\
\hline
\end{tabular}

\subsection{Data Collection}

This research was conducted in the $8 \mathrm{~m} \times 11 \mathrm{~m}$ fashion laboratory of Malang State University in a temperature of $33^{\circ} \mathrm{C}$ (Appendix 4). The room has 4 windows opened wide, 2 doors, and 1 blower that turns right and left $60 \mathrm{~cm}$ in diameter. The interview was conducted in three rounds: every single hour to the end of the workshop. The data collection also involved observing respondents' expressions by focusing on how the woolpeach fashion products absorb sweat within the three-rounded interview.In addition, the data was also documented in the form of written documents concerning the respondents' body measurements to be compared with the data collected through interviews and observations.

\subsection{Data Analysis}

The data analysis process moved through three stages: 1) data reduction, 2)data presentation, dan 3) the drawing of conclusion (Miles \&Huberman, 1992). Data redeuction means selecting the collected data and focusing on the significant ones, identifying the consistent themes and patterns, and reducing the unnecessary ones (Sugiyono, 2016:338). Afterwards, the data on comfortability of Msizedwoolpeach modest-fashion products were presented in a short overview, which is categorized based on the level of their comfortability (Appendix 3). A conclusion was then drawn from such data sources as interviews, observations, and documents gained duringthe research process.

\subsection{Data Validity Evaluation}

Data validity is important to assure in conducting research. An evaluation technique needs to be applied to assess the validity of data. In this research, the researcher applied a technique called methodological triangulation, especially source triangulation.

\subsection{Data Intepretation}

Data interpretation is the researcher's effort to comprehend the collected data so as to anwer the data questions. The interpretation of some categories used in this research is shown in the following table 3.3.

Table 3.3. Data Interpretation

\begin{tabular}{|l|c|}
\hline Categories & Clarification \\
\hline Disagree & Uncomfortable \\
\hline Somewhat disagree & Fairly uncomfortable \\
\hline agree & Comfortable \\
\hline Strongly agree & Very comfortable \\
\hline
\end{tabular}

\section{RESULTS AND DISCUSSION}

The exploration of the result of the research data deals with the aforementioned research focus, that is, to analyze comfortability of M-sizedwoolpeach modest-fashion products while worn in particular room. The related information was gained from some data-collecting techniques, including interviews, observations, and documents. The collected data were discussed basweed on the listed indicators, which include (1) heat insulation, (2) sweat absorption, (3) air permeability of comfortability of M-sizedwoolpeach modest-fashion products.

\subsection{Heat Insulation}

Heat insulation of a fashion product is its ability to conserve heat outside of the body, a hot temperature of the environment, so that the body of its users becomes hot. Fashion products with good heat insulation keep their users' body cool inspite of high temperature. In this research, some respondents wore M-sized modest-fashion products for three hours, and they were interviewed every hour to know the products' heat insulation. The researcher wrote of the heat insulation as follows.

In the first stage of data-collecting process, in the first onehour use, 20 respondents had varying opinions about the fashion products. On the one hand, a respondent said that he/she felt comfortable in the product in that he/she enjoyed performing the activity for an hour.Besides, eleven respondents had the same feelings. On the other 


\section{REFERENCES}

hand, three respondents felt nothing, neither heat nor M-sized woolpeach modest-fashion products for an hour.

\subsection{Sweat Absorption}

Sweat absorption of a fashion product can be detected from a fabric's ability to absorb beads of sweat, so that the user's body is not bathed in sweat running off his/her body. In this research, the fabric of which a fashion product is made iswoolpeach. Of sweat absorption the researcher wrote as follows.

As for sweat absorption of fashion products, the researcher collected information three times, conducted every one single hour. In the first one hour of wearing the products, four respondents felt hot while wearing the products in performing the activity in the room. After two hours of wearing the products, twelve respondents felt hot and beads of sweat began to stand out.Meanwhile, three respondents felt hot and their sweat spread after their wearing the products for three hours.In contrast, a respondent felt comfortable and did not soak in sweat although bustling with the activity in the room.

\subsection{Air Permeability}

Air permeability is a fabric's quality to inhale air outside the body into an area of a woven fabric and at the same time to pass it through the fabric.Air permeability can be felt when the air into and from the woven fabric flows easily, which in turn produces cold sensation during the air circulation.In the following paragraph, the researcher wrote of the air permeability.

Modest-fashion's fabric material's ability to inhale air into a hollow space between the woven fabric and the body and then blow it back through the fabric made eleven respondents recognize that modest-fashion products they were wearing were made of fabric material with good qualities to circulate air very well. However, two respondents stated the contrasting opinion that the products did not perform the job well; meanwhile, the other seven respondents had the mixed feelingthat they hardly felt the cold sensation.Of the three categories of respondents, those who felt that the fashion products had good air permeability, the ability to produce good air flow, formed the most - 11 of 20 respondents.

\section{CONCLUSION}

Given the finding, it can be concluded that woolpeach modest-fashion products are comfortable to wear even in the hustle and bustle of indoor activities. Such comfort results from woolpeach's being neither too thick nor too thin.Woolpeach is a mixture of silk, cotton, and synthetic fabrics. What is more, woolpeach is known to be light, smooth, and not transparent and produce a cold sensastion, which is comfortable and suitable to wear in tropical regions like Indonesia.
[1] Bin Nafisah,L A, 2015. Muslim Female Clothing Practice: An exploratory study of ancient and modern perception. Departement of Ancient Languages and Cultures, Faculty of Humanities University of Pretoria

[2] Bhatia, Dinesh., \& Malhotra, Urvashi. 2016. Thermophysiological Wear Comfort of Clothing: An Overview. India: Department of Textile Technology. Journal of Textile Science \& Engineering, (Online). (http://dx.doi.org/10.4172/2165$\underline{8064.1000250}$ ). Diakses 31 Maret 2017

[3] Dolce \& Gabbana's New Hijab Collection, 2017

[4] https://en.wikipedia.org/wiki/Modest_fashion, diakses 18 Maret 2018

[5] http://www.milazone.com/blog-285-detailsize-zoya.html, diakses 18 maret 2018

https://ommihijab.blogspot.co.id/2016/11/wol lpeach-wolfis-ciri-karakteristik-kualitas-kainwolfis.html

[8] Malik, Tanveer., \& Sinha, T. K. 2012. Clothing Comfort: A Key Parameter in Clothing. India: Shri Vaishnav Institute of Technology and Science. Article (Online). (http://www.google.co.id/amp/s/www.resear chgate.net/publication/294627343_Clothing_ comfort_A_key_parameter_in_clothing/amp ). Diakses 31 Maret 2017

[9] Kaplan \& Okur, 2007. The Meaning and importance of Clothing Comfort: A Case Study For Turkey. Turkey: Dokuz Eylul University Textile Engineering Departement, Izmir

[10] Sugiyono. 2012. Metode Penelitian Pendidikan Pendekatan Kuantitatif Kualitatif dan $R \& D$. Bandung: Alfabeta. 